AC 2007-2396: ENGINEERING TECHNOLOGY TRAINING IN SAUDI ARABIA: QUALITY TRAINING CHALLENGES AND LABOR MARKET NEEDS

Hamad Albadr, Riyadh College of Technology 


\title{
Engineering Technology Training in Saudi Arabia: Quality Training Challenges and Labor Market Needs
}

\begin{abstract}
:
Biomedical engineering developed in health care facilities around the world over the last four decades of the twentieth century. There was widespread recognition in professional and government circles of the technological sudden increase that had affected society in general and health care in particular.

Biomedical engineering applied with an early large emphasis on the maintenance, electrical safety, and electronics aspects of medical equipment. This encouraged the consideration of broader safety aspects in health care.

Biomedical Engineering Professionals who divides into two main categories: the Clinical Engineers (CE) or Biomedical Engineers and the Biomedical Engineering (Equipment) Technicians (BMET) required a special training to be qualified to be very trusted technicians.

In Saudi Arabia, as a developed country, the Government spends billions dollars annually expenditure on the health sector. The Ministry of Health has finalized plans to establish new hospitals and renovate and expand 324 existing hospitals and 1750 primary health care centers.

Long time ago, the health care facilities and medical companies were counting on the overseas professionals in the field of biomedical equipment marketing, installation, training, and maintenance. As far as twenty years ago, there were no Saudi professionals in the field of biomedical engineering/technology. Biomedical engineering introduced as a new field of study at King Abdul Aziz University ( KAAU), Jeddah in 1982, and King Saud University (KSU); Riyadh started in 1986.
\end{abstract}

The General Organization for Technical Education and Vocational Training (GOTEVOT), who founded in 1980 , set of laws require that the Organization should execute all programs related to technical education in various fields like industry, agriculture and commerce as well as all related to vocational training like in-service training in addition to conducting researchers and studies for upgrading national manpower performance and productivity efficiency.

In advance to open the new major, GOTEVOT had established the National Occupational Skill Standards for medical instrumentation (Biomedical) technician and developing a curriculum called " Developing A CurriculUM- DACUM" with participating of Biomedical technicians who were working in local biomedical engineering departments in local hospitals to define the job duties and the skills needed for these duties and Biomedical Technology Program started last year,2006, under Electronics technology department

There are two main problems that biomedical engineering departments in Saudi Arabia face. First, there is a lack of number of Biomedical Engineers and Biomedical Technicians. Second, the selection of medical equipments, their installation, safe operation, and maintenance which require extra care because of their high cost, and delicate and specialized nature. Currently, these functions are handled by contractors, local vendors, international companies, and/or left to unqualified hands 
The aim of this study is to understand the situation of Saudi Biomedical Engineering Departments, support and encourage Biomedical Engineering Departments to involve in repairing and maintaining medical equipment in the health care facilities. It is the first step for those entering biomedical professional field.

This research paper gives a general overview on the biomedical engineering departments through 23 questionnaires were collected all over the country to identify the structure, personnel, responsibilities and resources of the Biomedical departments and training programs in Saudi Arabia that been designed to meet the Labor Market Needs.

\section{Biomedical Engineering Overview:}

Before going to discuss what is now referred to as Biomedical engineering ,it is better to begin with considering first the development of biomedical engineering and, in turn, Biomedical engineering.

In the past engineering was defined as the facility to express the sources of power in nature for man's use and convenience. Today, modern engineering involves the application of scientific techniques, theories, and technology for the solution of social needs. That includes all engineers, and biomedical engineers in particular must deal with.

Biomedical Engineering is a field where concepts from Engineering, Mathematics, Computation, Physics and Chemistry are used to solve problems in Biology and Medicine.

Biomedical Engineering can be divided into four sub-areas:

1- Bioengineering focuses on pure research; for example, the study of the behavior of neurons and cardiac cells with the aid of mathematical models and simulations;

2- Medical Engineering is directed to the study, design and construction of instrumentation (mainly electronic), sensors, and prosthesis for the medical field;

3- Clinical or Hospital Engineering focuses in certification and testing of medical equipments; and hospital activities, such as design, adequacy and execution of installations, consulting for acquisition of equipments, training of maintenance teams;

4 - Rehabilitation Engineering aims the development of electronic and mechanical systems for the improvement of the quality of life of physically challenged people.

The American College of Clinical Engineering (ACCE), funded in 1991, ACCE is committed to enhancing the profession of clinical engineering. With members in the United States and abroad, the ACCE is the only internationally recognized professional society for clinical engineers, a Clinical (biomedical) Engineering is the field of engineering that supports and advances patient care by applying engineering and management skills to healthcare technology. (ACCE definition-1992)

As Biomedical engineering established in 1959 by a group of medical engineers, physicists and physicians met at the 2nd International Conference of Medical and Biological Engineering, in the UNESCO Building, Paris, France, to create an organization entitled International Federation for Medical Electronics and Biological Engineering. At that time there were few national biomedical engineering societies and workers in the discipline joined as Associates of the Federation. Later, as national societies were formed, these societies became affiliates of the Federation.

Biomedical engineering developed in health care facilities around the world over the last four decades of the twentieth century. There was widespread recognition in professional and 
government circles of the technological explosion that had affected society in general and health care in particular. A series of workshops held in 1972 provided a forum for the discussion of the need for an engineering approach to effect some control on this technology.

Three of the factors that can be cited as having had a great influence on the way in which Biomedical engineering has developed in the hospital:

1. The rapid influx of technology and its resulting instrumentation into the hospital primarily in the1960s and 1970s

2. The recognition of an electrical safety issue associated with the increase in biomedical instrumentation coming in contact with the patient

3. The move to develop a certification process for engineers in hospital clinical settings.

Certification influenced development of Biomedical engineering in three ways.

1- It established and crystallized the name of the field as Biomedical engineering.

2- It provided some assurance of the competency of Biomedical engineering practitioners to the health care facilities where they practiced.

3 - It tended to result in biomedical engineers defining themselves in terms of the certification process. The examination process in particular, which in the U.S. boards of examiners was heavily oriented toward electronics, had an effect on both the type of engineering people who went into the field and the educational programs that provided the training. The wide range of management and broad health care issues identified by such people as Rushmer and Caceres tended not to have as heavy an emphasis.

\section{The Role of Biomedical Engineering}

This previous background provides a basis for the understanding of the role Biomedical engineering occupies in health care today. Biomedical engineering developed with an early large emphasis on the maintenance, electrical safety, and electronics aspects of medical equipment. This encouraged the consideration of broader safety aspects in health care.

Biomedical engineer must provide education for nursing, medical, and paramedical staff to facilitate their understanding of present technology and future trends. In consultation with medical and administrative staff, he or she must ensure that equipment purchases and hospital designs and systems are optimal and that technology acquisitions are appropriate; he or she must engage in applied research and development at all levels to improve patient care and make provisions for the safe and effective use of technology.

\section{Responsibilities of Biomedical Engineering Department:}

According to the previous descriptive of the role of Biomedical engineering, the major responsibilities for the Biomedical engineering department are:

\section{A- Education}

Prime responsibility for making provisions for training and education associated with technology and instrumentation used in the hospital

1- Education of Biomedical engineering staff

2- Education of health care facility staff

\section{B- Clinical Research/Development:}

This include :

1- Design of new equipment, patient aids, and techniques to aid in patient care

2- Assistive devices

\section{Computing Applications}

On of the most important function of Biomedical engineering is development and management of hospital and patient information and data-acquisition systems. 
Certainly the everywhere attendance of computing in all functions of the hospital is well recognized.

\section{Facility Planning}

The application and proper use of technology entail the appropriate management of all resources, including equipment, personnel, supplies, and space. It is obviously important then that the requirements placed on a health care facility by a particular technology become part of the considerations for the technology and related equipment. However, it must also be reflected at a very early stage in the planning process in the planning and design of the facility itself..

\section{E. Systems Management}

This includes:

1- Systems analysis2- Design and evaluation of health care systems 3- Quality management

\section{F. Equipment Management:}

This includes:

1- Consultation with other health care staff in the planning and purchase of equipment

2- Prime responsibility for maintenance and modification of equipment.

The large number of individual devices in modem hospitals presents a unique set of problems in management and represents a major role for Biomedical engineering. This set can broadly be set parts into:

1. Planning Functional program review

2. New equipment planning

3. Renewal equipment planning

4. Acquisition Definition of Biomedical requirements

5. Survey of available equipment

6. Specification writing

7. Equipment evaluation

8. Generation of purchase documents

9. Vendor selection

10. Acceptance testing

11. Control Inventory management

12. Maintenance

13. Repair

14. Test and calibration procedures

15. Scheduled inspection

16. Safety program

\section{Biomedical Engineering Personnel:}

Biomedical Engineering Professionals divides into two main categories:

1- Clinical Engineers (CE) or Biomedical Engineers

2- Biomedical Engineering ( Equipment ) Technician (BMET)

As mentioned earlier, The American College of Clinical Engineering (ACCE) defines A Clinical Engineer (CE) as a professional who supports and advances patient care by applying engineering and management skills to healthcare technology". (ACCE definition--1992) This definition leads us to define Biomedical Engineering as" a brat of engineering that supports and advances patient care by applying engineering and management skills to healthcare technology".

Also some organization add another professional called "Biomedical Instrumentation Technology (BMIT )", who involves testing, maintenance, repair, and calibration of the equipment used to deliver health care. The Biomedical Instrumentation Technician (BMIT), 
who also known as a Biomedical Equipment Technician, or Biomedical Engineering Technician (BMET), works closely with other health care professionals. They are commonly part of the hospital engineering division. Specialization areas include clinical radiology, ultrasound, cardiac monitoring, nuclear medicine laboratory, respiratory care, and therapeutic equipment. Graduates find employment with hospitals, biomedical instrumentation manufacturers, and service organizations that specialize in biomedical instrumentation.

\section{Future Development of Biomedical Engineering:}

In keeping with the definition of Biomedical engineering as supporting and advancing patient care through application of engineering management and technology, it is important to recognize that the field of Biomedical engineering will need to continue to develop as health care develops. This will include developments both in sophistication, such as physiological functional imaging or highly integrated information systems, and in scope, such as wellness care or distributed clinical care.The spread of new or newly important diseases coupled with shifts in population composition will present challenges to health care systems everywhere. Finally, the economic impact of all these factors on health care systems needs to be taken into account.

\section{Biomedical Engineering External Factors}

While these changes in health care are occurring, there are other external factors that will also affect the Biomedical engineering field:

\section{A. Internationalization of science and technology.}

The science and technology used in health care are universal. Coupled with global manufacturing and international companies, it is clear that science and technology are worldwide in application.

\section{B. Integration of Technology.}

The examples provided by some of the preceding authors, it is evident that health care technology is sophisticated and cross-disciplinary. The application of communications theory to improving the accuracy and speed of DNA sequencing is such an example. In addition, devices are increasingly interdependent and intercommunicate freely as they are combined into systems.

\section{Communications technology.}

Information is the new currency of modem health care delivery. The data generated at the instrument site must be transformed into information usable for diagnosis and therapy. The health care facility or system must have the ability to move that information to the patient care site. Considerations of information storage and transfer and the protocols for making such transfers are all now part of health care's technology management decisions.

\section{Regulation of health care technology.}

The health care medical device field is heavily regulated in all countries of the world. The impact this has on the application of technology at an individual hospital level varies with the sophistication of the hospital. However, three examples of international standards that influence the safety and effectiveness of every medical device in the hospital illustrate the pervasive nature of these standards and regulations. These three standards are the medical electrical standard, IEC 60601, the ISO quality-management standard, ISO 13485, and the ISO risk-management standard, ISO 14971. Biomedical engineering personnel need to be fully informed about each of these standards and the impact they have on their hospitals.

\section{Biomedical Engineering in the Kingdom of Saudi Arabia}

\section{Introduction:}


The Kingdom's policy on health is simply expressed - the provision of free health services for the benefit of all the citizens of Saudi Arabia - and King Fahd has shown, throughout his reign, a very real understanding of the importance of adequate health provision for those who need it, both within and outside the Kingdom.

The Ministry of Health policy reflects the Government's national development strategy, which is committed to improving the quality of life of the Saudi people, and to helping them to participate fully in the development plan and to benefit from it.

To carry out this policy, the Ministry of Health provides a whole range of health services (preventive, corrective, educational and rehabilitative) to the entire population. This is achieved through a network of hospitals and primary healthcare centers which are distributed throughout the country.

To meet the increased demand for healthcare, the Government's annual expenditure on the health sector in 2000 was estimated at 13 billions Saudi Reials (3.5 \$US billions). The Ministry of Health has finalized plans to establish eight new hospitals and renovate and expand 324 existing hospitals.

The following statistics, colleted in 2001, illustrate the progress made in healthcare provision in the Kingdom:

\begin{tabular}{|l|l|}
\hline Provision Number Hospitals & 324 \\
\hline Beds & 46,622 \\
\hline Doctors & 31,983 \\
\hline Nurses & 67,421 \\
\hline Assistants Health Personnel & 38,519 \\
\hline
\end{tabular}

\section{Biomedical Engineering Background in Saudi Arabia:}

Biomedical Engineering has been introduced in the health care environment extended time ago in Saudi Arabia. It goes back to more than three decades where most of the health cares providers were government facilities. They accustomed entrust $t$ he medical equipment companies who care for of their products within the health care facilities. There were some complications in this process as the health care facilities have to obey the companies' terms, conditions and roles, which cost the facilities a lot of money. In the last two decades the developments in the field of medical equipment were very rapid and the number of health care providers increased very rapidly including private businesses.

\section{Biomedical Engineering Technology Training :}

To meet the requirements for the Kingdom's healthcare, it was necessary to complement the hospital building program with an equally ambitious medical training program.

Medical training institutes were established at Abha and in the Holy City of Madinah. Training centers were set up in the King Abdul Aziz University in Jiddah and in the King Faisal University and a 760-bed teaching hospital was located in the King Saud University campus outside Riyadh.

The Kingdom's healthcare provision has been so successful that it is cited by the World Health Organization as a model for the developing world.

Since public health is a high priority subject in the national development plan, the Kingdom has an impressive number of hospitals and they are equipped the latest and most sophisticated 
medical equipment. The selection of these equipments, their installation, safe operation, and maintenance require extra care because of their high cost, and delicate and specialized nature. Currently, these functions are handled by contractors, local vendors, international companies, and/or left to unqualified hands. It is understood that the numbers of qualified personnel are shortly required and they should be trained to carry out the above-mentioned duties.

Long time ago, the health care facilities and medical companies were counting on the overseas professionals in the field of biomedical equipment marketing, installation, training, and maintenance. As far as twenty years ago there were no Saudi professionals in the field of biomedical engineering/technology. Biomedical engineering introduced as a new field of study in the electrical engineering department of engineering college of King Abdul Aziz University, Jeddah in 1982.

\section{Biomedical Engineering Training Programs in Saudi Arabia : \\ Biomedical engineering at King AbdulAziz University:}

The curriculum of the biomedical engineering at KAAU is oriented to produce biomedical engineers who can participate and cooperate in improving and developing the health care services in Saudi Arabia. It is considered to be as part of more general field of bioengineering, which combines the mathematical skills, the physical science knowledge and the analytical ability of the engineer. Also the knowledge and understanding of biological systems of the life scientist in order to develop solution to engineering problems associated with living systems.

The program of study for the Biomedical Engineering Option includes the general university requirements ( 6 courses), the general college of engineering requirements (19 courses), the general electrical engineering require meets (11 courses), and the biomedical option requirements of 14 compulsory and 2 elective courses. Like every other department and option in the college of engineering, the total number of credit hours for graduation is 165 .

\section{Biomedical Engineering at King Saud University:}

There is another department of Biomedical Engineering at the College of Applied Medical Sciences (AMS) of King Saud University (KSU); Riyadh started in 1986. There are some differences between these two colleges as first college is concentrating on the engineering perspective where the other college focused on the medical viewpoint. Most of those graduated students have the intention to work in the Biomedical engineering/technology field within the health care environments.

Two years ago , King Saud University, has established a two-year program that called Biomedical Engineering technology at several community colleges around the kingdom .

\section{Biomedical Engineering Technology Training program in Technology College:}

Establishment of the General Organization for Technical Education and Vocational Training (GOTEVOT) was a positive step taken by the government to guarantee the building of a solid base of qualified and capable technical and vocational cadres to deal with the continuing development aspects of all levels. This step came after a detailed study for the need of Saudi manpower to meet the Kingdom's development process. Officials found that the best way to develop this kind of education was through the establishment of a general organization to be responsible for the implementation of the manpower development plans. 
GOTEVOT regulations stipulate that the Organization should execute all programs related to technical education in various fields like industry, agriculture and commerce as well as all related to vocational training like in-service training in addition to conducting researchers and studies for upgrading national manpower performance and productivity efficiency

This program started this year 1426/1427(2006) in college of technology - Riyadh under Electronics technology department.

The kingdom of Saudi Arabia has witnessed lately a proliferation of clinics, medical centers and hospitals, all equipped with up to date high-tech medical instrumentation, varying in sophistication and complexity, from simple digital thermometers, to wholly computerized scanner systems. This has given rise to a tremendous demand for highly qualified Saudi personnel at all levels, at the Associate Degree level (Assistant Engineer) in particular

\section{General Objectives of the Biomedical Technology Major}

The goal of the Biomedical Technology Division is to prepare highly qualified Assistant Engineers specialized in high-tech medical equipment, to stand up to the ever changing world of various medical instruments.

The present program proposes to attain this objective through a well balanced curriculum that will provide the student with the required theoretical information and practical skills. For this purpose, it offers basic scientific and technical knowledge through lectures and hands on experimentation on up to date medical instrumentation in the laboratories and workshops. Furthermore a whole semester is reserved within the framework of this program to cooperative training in hospitals.

This program shall be implemented within Electronics Technology Departments of Riyadh Colleges of Technology. Basic courses are common to the existing Industrial Electronics and Control program. These courses provide the student with basic knowledge and practical skills in Basic Electricity, Electronics and Computers. The major emphasis in this major is on medical instrumentation, where a selection of courses is offered to the student such as Basic Medical Knowledge, Biomedical Instrumentation, Biomedical Imaging, biomedical Laboratory Instrumentation, Computers in Biomedical Instrumentation and Biomedical Instrumentation Workshop.

\section{National Skill Standards and the Curriculum for Biomedical Technicians in Saudi Arabia:}

Directorate General For Curricula Design \& Development at Organization for Technical Education and Vocational Training had designed the National Occupational Skill Standards for Medical Instrumentations Technician.

The curriculum is considered as an important element in the educational and training process because it has the desirable level of knowledge and skills to be acquired by the students and trainees.

The General Organization for Technical Educational and Vocational Training (GOTEVOT) is the assigned authority for qualifying and training the Saudi youth to participate in the vocational and professional works; and to give them the skills required by the labor market. For this reason, the organization is committed to go forward with the rapid development of technological process in this field.

In advance to open the new major, the curriculum Department hold "Developing $\mathbf{A}$ CurriculUM- DACUM" , workshop in 1422 ( 2002) with participating of 10 Biomedical 
technicians who were working in local biomedical engineering departments in local hospitals. The workshop defined the job duties and the skills needed for these duties.

The concept of developing National skills standards emerged from the idea that the practitioners are the most expert specialists to Determine any profession according to precise descriptions for task, duties, skills, knowledge, and the behaviors required for the professions. GOTEVOT has benefited from these expert specialists, from the labor market needs, working alongside the GOTEVOT educational experts. This has enabled the precise definitions, Objectives and task for each technical specialization to be completed.

More than twenty fife specialists and technicians had worded as Members of Working Committee on Preparing the National Skill Standards for the Trades and Members Of Specialist Committee For The Medical Instrumentations Technicians. Also , the biomedical technician from furious hospitals had worked through The Panel Members In The Job Analysis Workshop For The Trades.

\section{Job Requirements:}

The DACUM assigned duties and tasks, and general knowledge and Skills, that required for the biomedical technicians:

\section{1- : Duties and Tasks}

There are six Duties and each of them has five tasks for daily works for the biomedical technicians. These are:

A - Observe the daily work order that includes five tasks:

1- Receive notification of defects

2- Classify tasks according to their importance

3- Have a preliminary checkup of the instrument

4- Determine the service responsible for maintenance

5- Coordinate with the concerned services

B- Carry out preventive maintenance, that includes five tasks::

1- Schedule preventive maintenance tasks

2- Coordinate with the concerned services

3- Prepare suitable tools and test devices

4- Execute preventive maintenance.

5- Prepare a report

C- Repair the mechanical failures, that includes five tasks::

1- Inspect the instrument from outside

2- disassemble the instrument

3- Identify the failure location

4- Dismantle the damaged parts

5- Repair the mechanical parts

D- Repair the electrical failures, that includes five tasks::

1- Inspect the instrument from outside

2- Disassemble the instrument

3- Identify the failure location 
4- Dismantle the damaged parts

5- Repair the electrical parts

E- Repair the electronic failures, that includes five tasks::

1- Inspect the instrument from outside

2- Disassemble the instrument

3- Identify the failure location

4- Dismantle the damaged parts

5- Repair the electronic parts

F- Assemble new (just arrived) medical instruments, that includes five tasks:

1- Ensure the parts of the instrument are complete

2- Ensure the parts of the instrument are safe

3- Assemble parts of the instrument

4- Check the instrument performances

5- Prepare a technical data base for new instruments

\section{2- General Knowledge and Skills:}

There are 14 General Knowledge and Skills required (in Percentage) for the biomedical technicians:

1. Ability to use advanced instruments $100 \%$

2. Ability to deal with others $100 \%$

3. Acquaintance with English language $97.9 \%$

4. Knowledge of Technical Terms 97.9\%

5. Ability to take appropriate decisions $97.9 \%$

6. Ability to write reports $97.9 \%$

7. Ability to participate in teamwork $97.9 \%$

8. Ability of using first medical aid instruments $95.8 \%$

9. Knowledge of symbols and medical terms $95.8 \%$

10. Innovative skills $91.7 \%$

11. Ability to deal with patients $91.7 \%$

12. Communication skills $89.6 \%$

13. Ability to use computer $85.4 \%$

14. Ability to deal with female $85.4 \%$

\section{The Fist 25 tasks arrangement according to their percentage:}

1. Assemble new (Just arrived)Medical instruments : Ensure that the parts of the instrument are safe (100\%)

2. Assemble new (Just arrived) Medical instruments: Assemble the parts of the instrument $(96.8 \%)$

3. Assemble new (Just arrived) Medical instruments : Check the instrument performances $(92.8 \%)$

4. Repair the mechanical Failures : Repair the mechanical parts $(88.5 \%)$

5. Repair the Electrical Failures : Repair the electrical parts $(88.5 \%)$

6. Repair electronic Failures :Repair the electronic parts $(88.5 \%)$

7. Observe the daily work order : Arrange an appointment for Troubleshooting (80.7\%)

8. Assemble new (Just arrived) Medical instruments :Prepare a technical data base for new instruments $(79.7 \%)$

9. $9 \mathrm{~F}$ Assemble new (Just arrived) Medical instruments : Ensure that the parts of the

10. Instrument is complete $(76.2 \%)$ 
11. Observe the daily work order : Determine the performance of The medical instruments $(75.2 \%)$

12. Repair the mechanical Failures : Identify the failure location (73.1\%)

13. D Repair the Electrical Failures : Identify the failure location $(73.1 \%)$

14. Repair electronic Failures : Determine the fault location (73.1\%)

15. Observe the daily work order: Coordinate with the concerned Services $(70.1 \%)$

16. Carry out preventive maintenance : Coordinate with the concerned Services $(63.4 \%)$

17. Repair the mechanical Failures : Disassemble the instrument (63.2\%)

18. Repair the Electrical Failures : Disassemble the instrument (63.2\%)

19. Repair electronic Failures : Disassemble the instrument (63.2\%)

20. Repair the mechanical Failures :Inspect the instrument from Outside (60.4\%)

21. Repair the Electrical Failures : Inspect the instrument from Outside (60.4\%)

22. Repair electronic Failures : Inspect the instrument from outside (60.4\%)

23. Carry out preventive maintenance : Schedule preventive maintenance task $(58.1 \%)$

24. Assemble new (Just arrived) Medical instruments:Participate in the preparation of a user's guide for medical Instruments( $57.7 \%$ )

25. Repair the mechanical Failures : Dismantle the damaged parts $(57.6 \%)$

\section{Analysis and Results}

\section{Problem Background:}

Biomedical engineering technology has affected every aspect of our lives. It has particularly reshaped medical care in the last three decades, and engineering professionals have become intrinsically involved in many efforts. Biomedical Engineering departments in Saudi Arabia have emerged with a general objective of assisting in the struggle against disease and disability by providing tools and techniques for research, diagnosis and treatment.

Most of the health service in the Kingdom runs on contract basis and employees change frequently. Thus, it is not possible to find the same experienced trainers all the time.

Some of the health care facilities have their own maintenance teams, Clinical /Biomedical engineering department is one of these maintenance teams who care for all medical equipment within the facility. Almost all of the maintenance staff is -foreigners- non Saudis. The problem started when the health care facilities demand Saudiization of such technical job positions. The Biomedical equipment technicians are one of those positions that required to be fulfilled.

The main problem Biomedical engineering departments in Saudi Arabia are the lack of number of Biomedical Engineers and Biomedical Technician. For example, there are only 96 student graduated from King Abdul Aziz University in Biomedical Engineering from 1985 to 2000 where $20 \%$ are non-Saudi national. $50 \%$ of the remains where joined the government health care facilities, $10 \%$ changed their professional career and the rest joined private facilities and/or medical companies .The Saudi Biomedical Engineers' hands on working are very low comparing to the number of health care facilities and/or medical companies. From the above data, the number of graduates working within the health care facilities and/or medical companies are very low which shows that the number of Biomedical engineers per number of hospitals and/or medical companies is one Biomedical engineer against five or more hospitals and/or medical companies. Obviously, there is a deficiency in the Biomedical Engineers. 
Even tough most of the Biomedical Engineering Departments in Saudi Arabia apply the US standards but they are very rare in Saudi Arabia and that would be due to confusion of medical instrumentation for Biomedical Engineering Departments (engineers and technicians) that especially organized for health care facilities within the Saudi Arabia health care environments.

The aim of this study is to understand the situation of Saudi Biomedical Engineering Departments, support and encourage Biomedical Engineering Departments to involve in repairing and maintaining medical equipment in the health care facilities It is the first step for those entering biomedical professional field.

\section{Case of Study:}

\section{Introduction:}

As a proposed study from this research to get an overview about biomedical engineering in Saudi Arabia, I used the International Survey of Biomedical Engineering Departments by Mariana Glouhova , Department of Medical Physics University of Patras, Greece that she used in 1998.

My present survey, launched in January 2003, was performed to identify the structure, personnel, responsibilities and resources of the Biomedical departments in Saudi Arabia .More than 65 questionnaires were distributed all over the country, The results are briefly presented below.

\section{Study Observations:}

These are most observations on this study:

\section{1- Average Number of Hospital Beds Vs. Number of ICU (intensive-care unit) Beds}

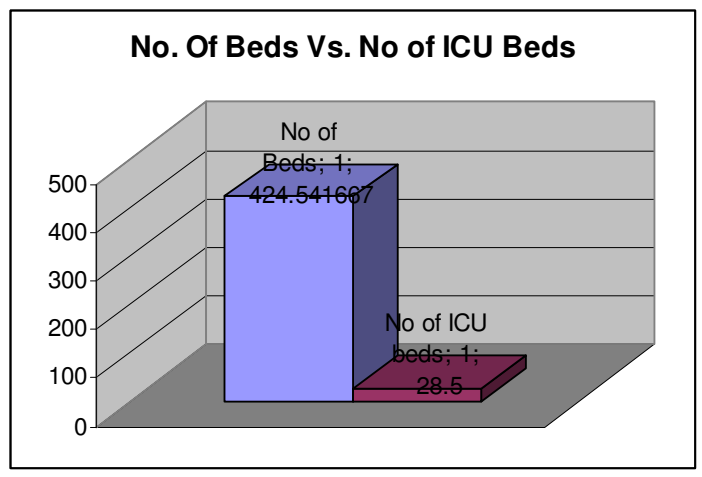

5,Approximate (replacement) value of the biomedical equipment in the hospital (in US Dollars) and Approximate budget for new biomedical equipment per year (in US Dollars) : 


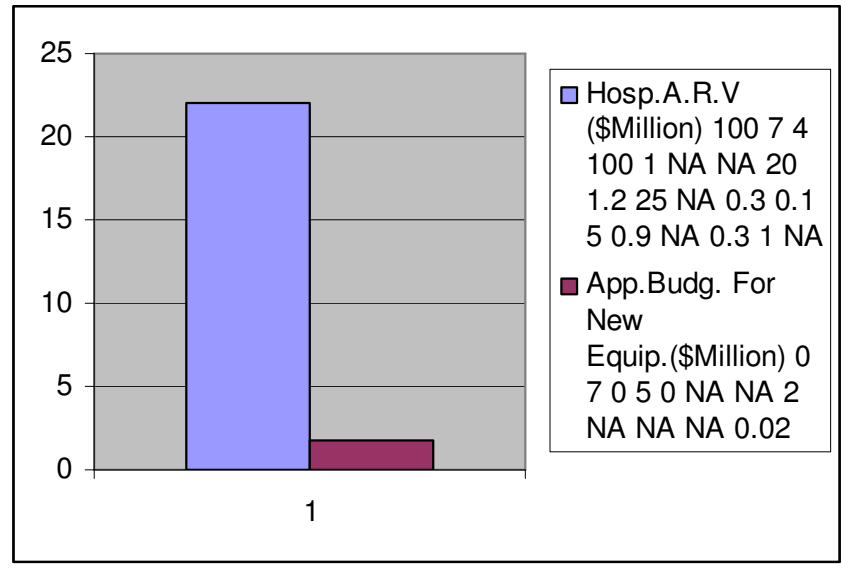

Engineering Department (CED) Profile

- Structure

6- The Biomedical Engineering services function as a separate department or part of other

\section{7- How old are CED's?}

CED's established in Saudi Arabia hospitals as an average for 16.5 years in each hospital :

This means that the CED is still new in Saudi Hospitals.

\section{8- Are you satisfied from the reporting authority? :}

As result of The Biomedical engineering services function as a non separate department by $63 \%$, there $75 \%$ CED's are satisfied from the reporting authority.

The majority of responses were from departments that exist as separate units. Few answers came from hospitals where the Biomedical engineering services function as a part of another department.

More than $75 \%$ of all respondents, however, were satisfied with their reporting authorities despite the fact that they vary greatly in the different countries.

\section{9- How much is the allocated space in $\mathrm{m}^{2}$ :}

$160 \mathrm{~m}^{2}$ is the allocated space in $\mathrm{m}^{2}$ which means there a quite enough space.

The majority of responses were from departments that exist as separate units. Few answers came from hospitals where the Biomedical engineering services function as a part of another department.

More than $75 \%$ of all respondents, however, were satisfied with their reporting authorities despite the fact that they vary greatly in the different countries. 
- Personnel

Number employees, qualification, average age and years of clinical experience (specify the numbers in each box)

10- Number employees of CED Personnel.

Average No is 9.875 persons; this number divides in different categories:

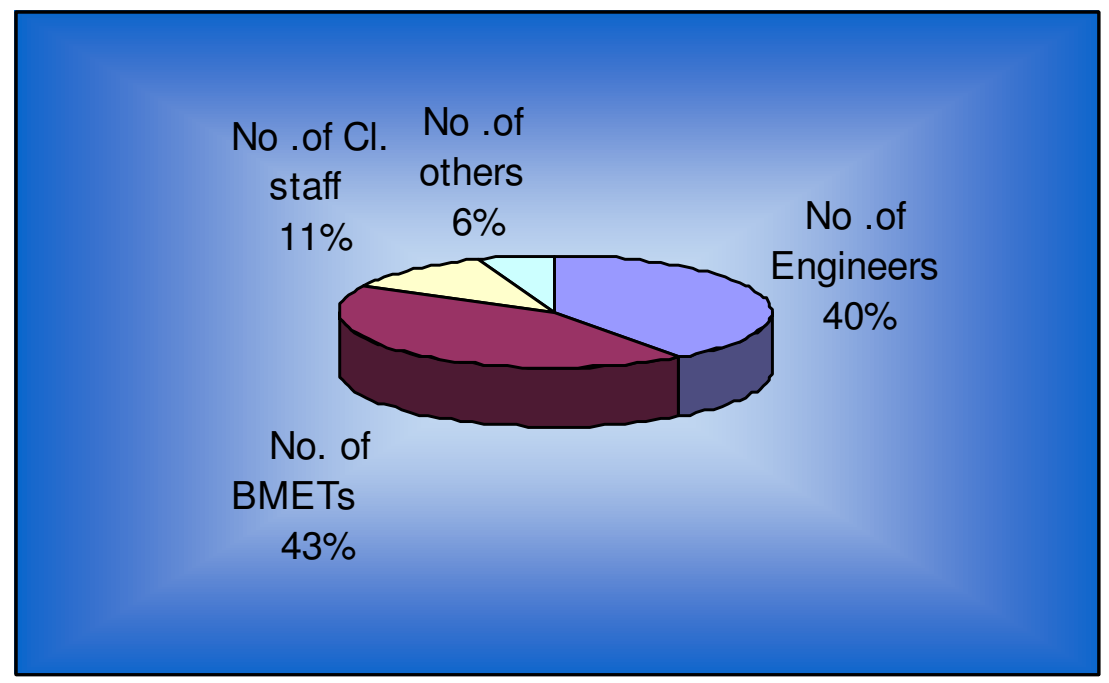

11- Average age of CED Personnel and Average Experience of CED Personnel:
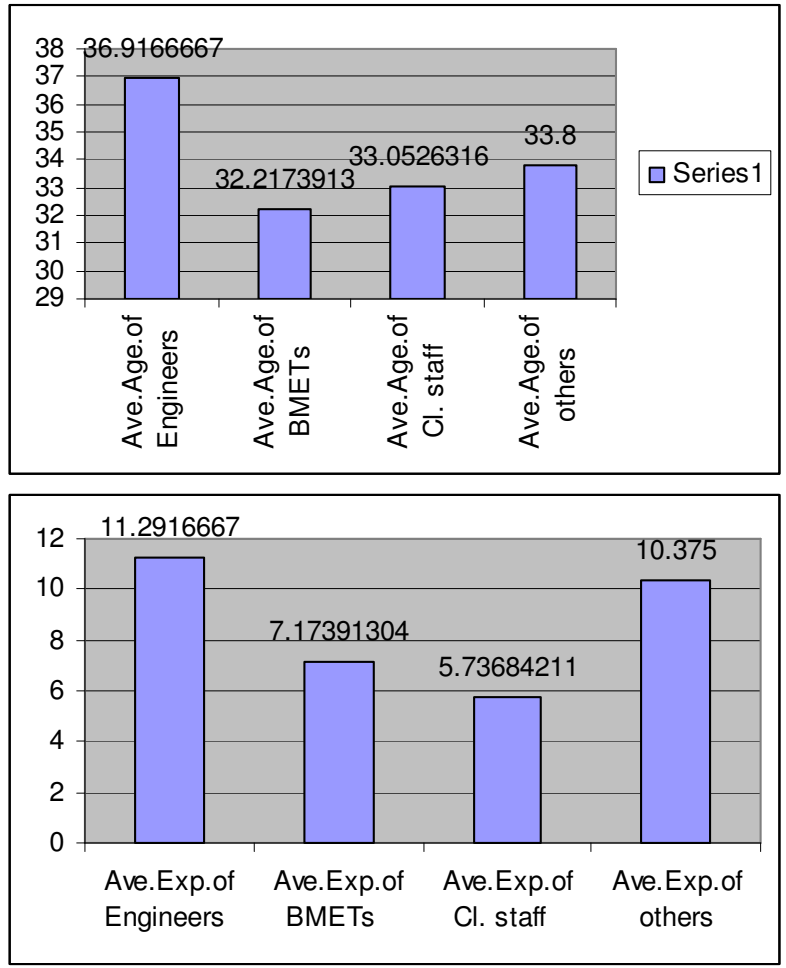
13- How many of the employees are women (excluding the clerical staff)?

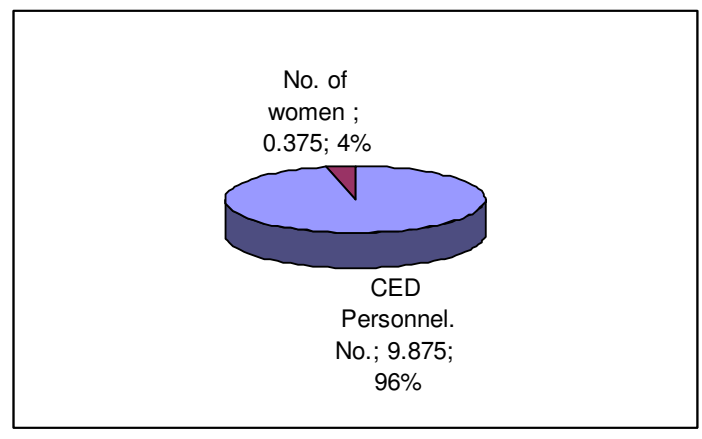

Because of the privacy of the Saudi Culture this rate need to be increase.

14. Is certification required in your department for biomedical engineers and BMETs ? Because the misunderstanding of the meaning of "certification", these answers conceded not to be accurate, however these answers are:

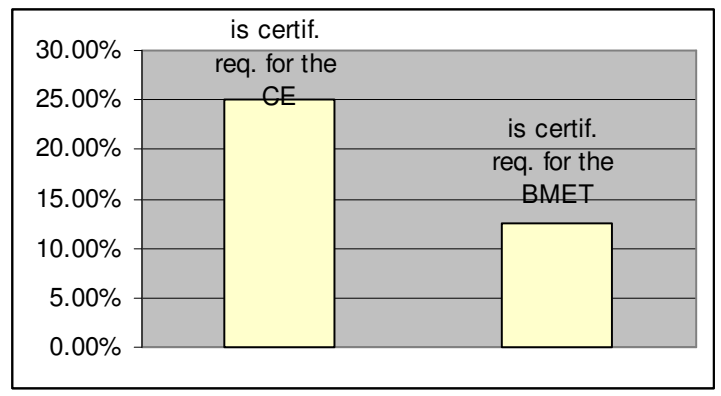

16. How many are members of national and/or international professional associations in your department for Biomedical engineers and BMETs ?

Because the misunderstanding of the meaning of "certification", these answers conceded not to be accurate, however these answers are:
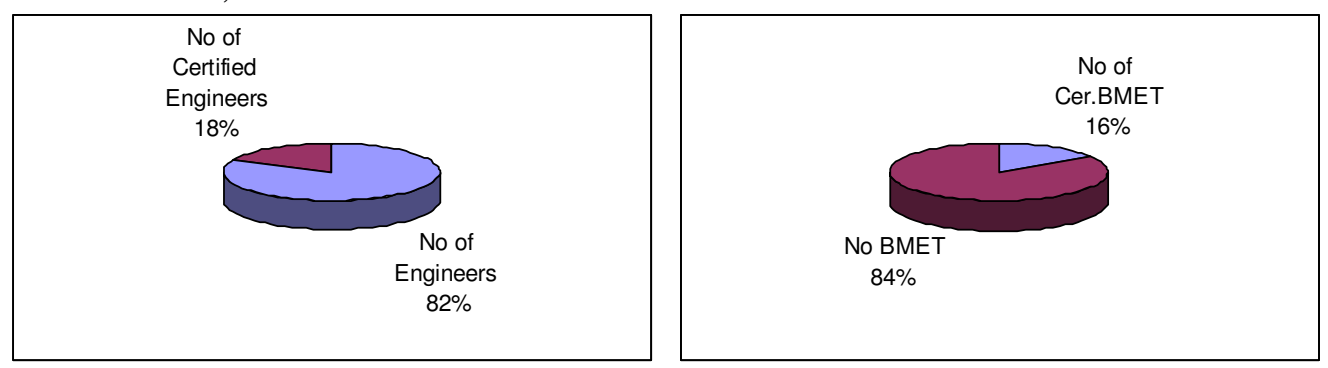

17. How many are members of national and/or international professional associations?
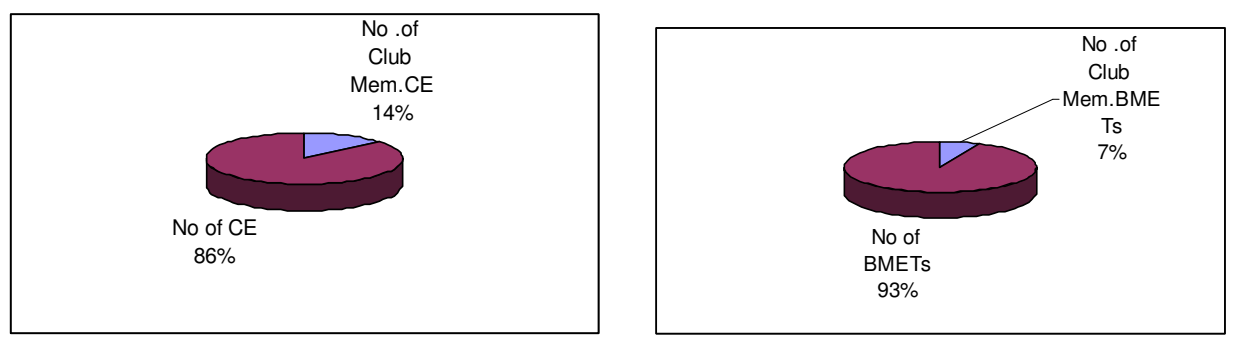


\section{How often do the CED personnel take training courses Every 24 months ?.}

There is very low frequency (once every two years) of training courses of CED personnel appears in most cases.

\section{Responsibilities:}

19. Number of devices supported by the CED.

The average number of devices supported by the CED is 5400 devices in each hospital.

20. Approximate (replacement) value of the biomedical equipment under the CED management (in US million Dollars).

The average for the hospitals who are responded for this question is 20 US million Dollars .The deportments in these answer are very vary as shown below.In these following activities about the department reduced to show the general activates not to compare Biomedical Engineer with BMETs.

\section{Department activities:}

\begin{tabular}{|l|l|}
\hline Department activities & Average $\%$ \\
\hline 1. Equipment Inventory & 5.8333333 \\
\hline 2. Preventive Maintenance (PM) & 30.590909 \\
\hline 3. Corrective Maintenance (CM) & 31.583333 \\
\hline 4. Pre-purchase Consultation: & 9.4583333 \\
\hline 5. Acceptance Testing (nncoming Inspections) & 6.4583333 \\
\hline 6. Management of Service Contracts & 4.7083333 \\
\hline 7. Risk Management & 2.5 \\
\hline 8. Quality Control & 3.3333333 \\
\hline 9. Education and Training & 5.25 \\
\hline 10. Research and Development & 1.375 \\
\hline 11. Other, please specify & 0 \\
\hline
\end{tabular}

It is very clear that Preventive Maintenance (PM) and Corrective Maintenance (CM) take most of the CE personnel time which is ore than $60 \%$.. in the same time other activities have very low in time .

\section{Department Resources:}

For this section, because the misunderstanding of the meaning of "approximate (replacement) value", these answers considered not to be accurate. Also, in most hospitals, the Biomedical engineering doesn't have this kind of separate budget for these activities. These sustentions are:

1- Specify the approximate (replacement) value of test equipment as a percentage of the replacement value of the biomedical equipment inventory under the CED management.

2- Specify the approximate (replacement) value of spare parts inventory as a percentage of the replacement value of biomedical equipment inventory under the CED management (if you keep a spare parts inventory).

3- How much is the budget of the department (if you have a separate budget) as a percent of the equipment value supported?

23. Department satisfactory about personnel, area, available test equipment, documents, and inventory

1. Is the number of personnel adequate? 
2. Is the provided occupancy area adequate?

3. Is the available test equipment adequate for performing your duties?

4. Is the parts inventory adequate?

5. Is the available technical (service) documentation adequate?

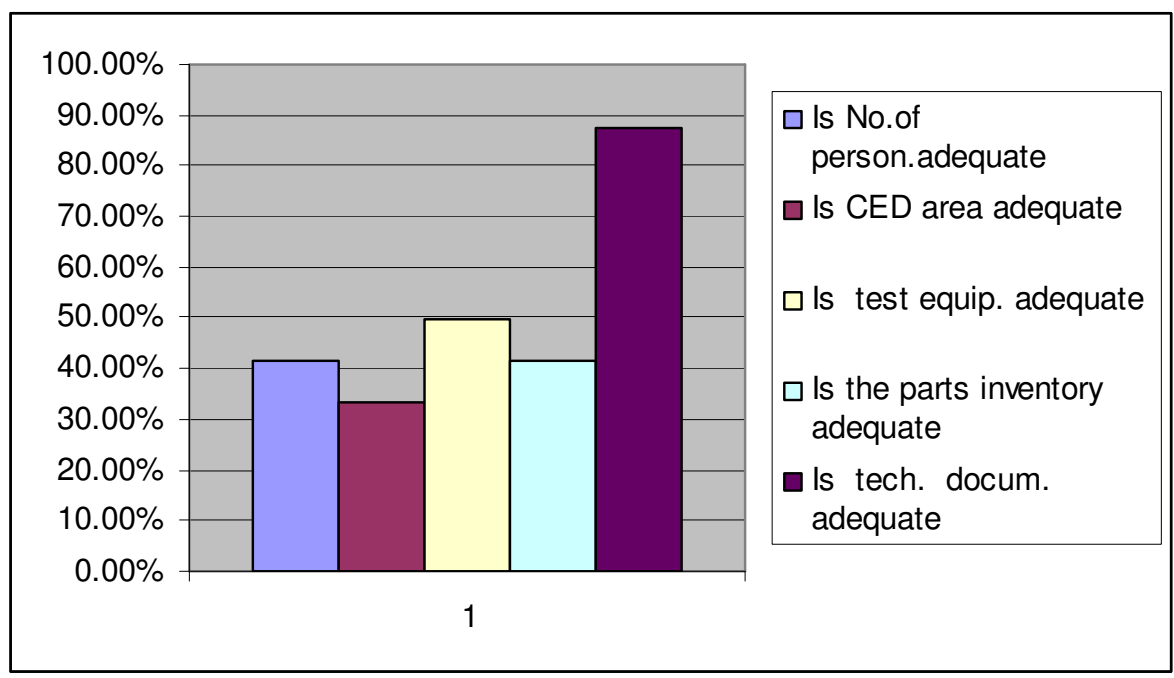

24. Additional personnel required: for Engineers and BMETs for each hospital as an average.

Number of Additional Engineers Required $\quad 0.54$

Number of Additional BMETs Required $\quad 1.625$

\section{Equipment management:}

1. Do you have a computerized system for management for the inventory and the maintenance of the equipment? $87.50 \%$

2. Do you have a quality assurance program? $33.33 \%$

3. Do you use a productivity index to measure staff performance? $54.17 \%$

4. Do you feel that the CED in your hospital is well accepted and its work recognized? $91.67 \%$

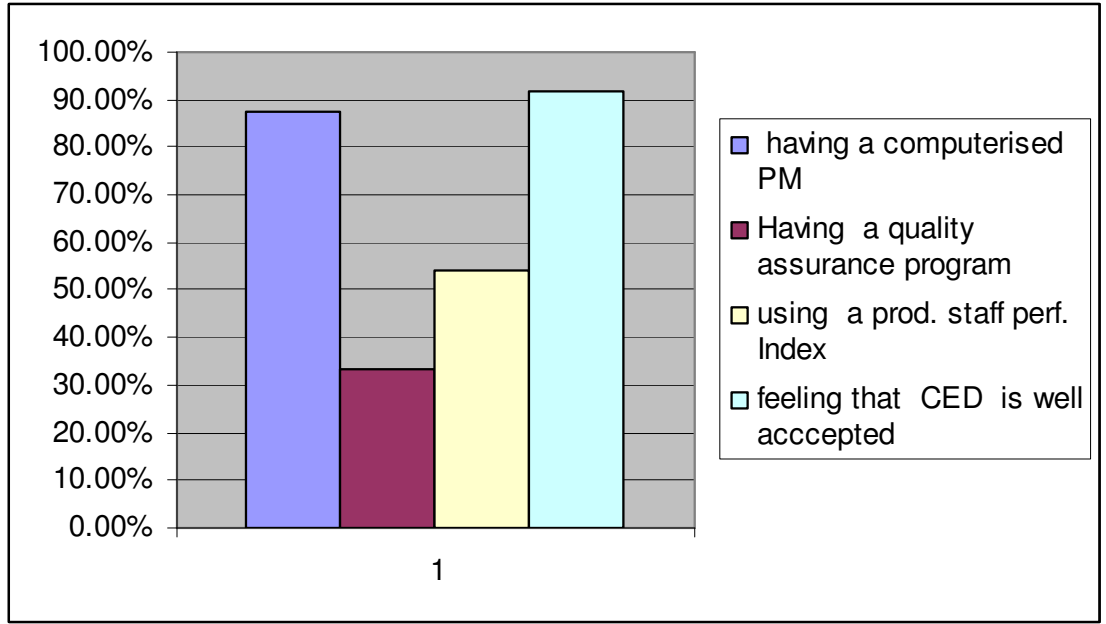




\section{Preventive maintenance program (PM)}

Number of devices supported by the CED

Number of devices in the database
5400

3131.96

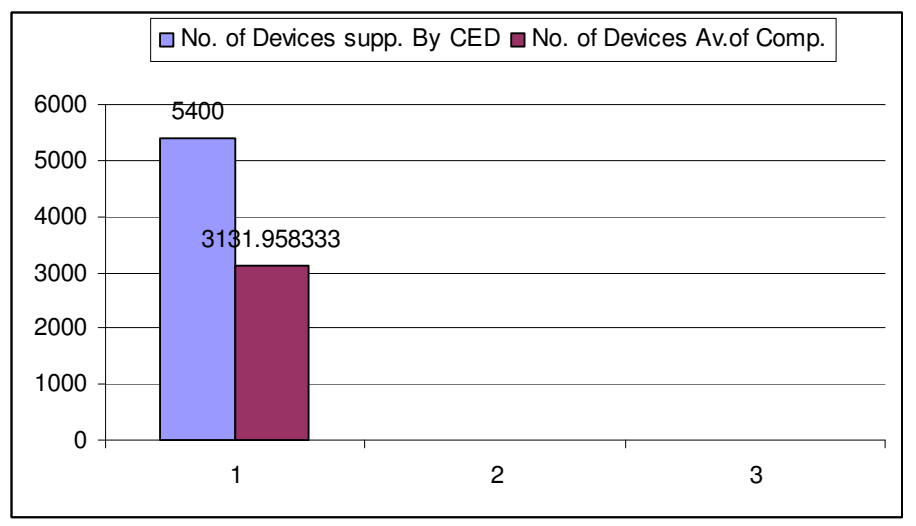

\section{Conclusions and recommendations:}

This study gives a general overview about the Biomedical engineering departments in 23 hospitals in Saudi Arabia as only 7\% from all hospital 324 in Saudi Arabia..

This research paper focuses on Biomedical engineering in Saudi Arabia that includes general over view on Biomedical engineering, Biomedical engineering departments in Saudi Arabia, and the field survey.

In Chapter 1, There is an Overview on Biomedical Engineering that starts with Introduction and definition of Biomedical and Clinical Engineering, Biomedical Engineering .This chapter covers also The Biomedical Engineering Development witch covers a Biomedical Engineering Development Factors, Certification of Biomedical Engineering :, The Role of Biomedical Engineering, and . The Functions of Biomedical Engineering Department. After that this chapter covers Biomedical Engineering Personnel who are Clinical Engineers (CE) and Biomedical Engineering Technician (BMET). Future Development of Biomedical Engineering: and Biomedical engineering External Factors is the last part of this chapter.

In Chapter 2, there is an overview on Biomedical Engineering in the Kingdom of Saudi Arabia that includes: Health Care in Saudi Arabia that covers Role of the Ministry of Health and Biomedical Engineering Background in Saudi Arabia.

This part brings in some activities and example, Training Programs in the university, colleges, and high institutes. After that there is a section gives an overview about Biomedical Engineering Departments in Saudi Arabian Hospitals.

Chapter 3, in this study focus on the Analysis and Results of this research that gives: Problem Background, Problem Statement, and Purpose Statement: 
The main chapter Case of Study: includes Number of collected surveys are 23, Study Observations in 26 categories to compare between these hospitals and departments.

Over all, this study is not enough to achieved the goal to get an over view about the Biomedical engineering departments in Saudi Arabia because it is not easy to they are lacking of getting an access for these information. Also these sorts of qualified personnel who fill out and the survey in some hospital .Also, the lack of Biomedical Engineering department organization that not has the power or decision to give permission for this kind of information especially in some military hospital or to gave the finical information.

Finally, this study did not answer most the question of the study and the survey.

There some factor that guided to this result:

1- Number of Collected Surveys is 7\%, which very low .But because the limitation of time (only three weeks), central management, and very slow process in some hospitals.

2- The lack of understanding of some questions and field because of most of managers either not a professional in the field or they not have an access for these information.

3- Limitation of time for this field study was only three weeks which need more time to follow up about collecting surveys.

After reviewing the result of this survey, I recommend to review and rewrite the survey to make easier to understand and easy to answer. Also I will recommend these following plan and solution for the next time to apply the survey:

1- Building a data base about the hospitals in Saudi Arabia as will as othe country that I want to apply the survey to them.

2- By making a good connection with the ministry of health and other central management system in each sector .for example: ministry of defense, ministry of interior, National Guard, Campers of Commerce.

3- Building a team work from different health systems and some departments and university to follow up the process and collection data.

4- Attaching an explanation and directions to help for how to fill out the survey

5- using many ways to send and to collect the information by :

a- Building a web site that contains this survey, which my next step to spread the survey. This will make easier to fill and to collect the data.

b- Using a regular mail and the fax to send the survey. 


\section{References:}

1. Introduction to Biomedical Equipment Technology (4th Edition), Joseph J. Carr, John M. Brown, Prentice Hall; 4th edition ,2000

2. CRC Handbook of Clinical Engineering

, Barry Feinberg, Boca Raton, 1980

3. Handbook of Biomedical Engineering (Handbooks in Science and Technology), Jacob Kline (Editor), Acadimic press, San Diego, 1988

4. Applied Clinical Engineering by Barry N. Feinberg, Prentice- hall, New Jersy, 1986

5. American College of Clinical Engineering (ACCE), "What's a Clinical Engineer?", http://www.accenet.org/

6. King Faisal Specialty Hospital and Research Center (KFSHRC): Facts and Figures 2001, King Faisal Specialty Hospital and Research Center, Riyadh, Saudi Arabia,2001

7. The Department of Biomedical Engineering King Faisal Specialty Hospital and Research Center, Biomedical Engineering Services, http://www.kfshrc.edu.sa/biomed/

8. Health Care in Saudi Arabia, http://www.saudinf.com/main/h91.htm

9. Healthcare Provision Statistics, 2001, Ministry of Health, http://www.moh.gov.sa/index_e.htm

10. Biomedical Engineering Department (BME). (2000). Biomedical Engineering Graduates King AbdulAziz University.

11. General Objectives of the Biomedical Instrumentation Major, College of Technology,Riyadh,2001

12. Diagnostic Radiography, T.M. Kolawale, Ministry of Health, Saudi Arabia.

13. National Occupational Skill Standards For Medical Instrumentations Technician, General Organization for Technical Education and Vocational Training, Directorate General For Curricula Design \& Development, Riyadh , 2002 